\title{
INTERVENSI INKLUSIF SUKAN TERHADAP MURID GANGGUAN KECELARUAN TUMPUAN DAN HIPERAKTIF (ADHD)
}

\section{(SPORT INCLUSION INTERVENTION TOWARDS ATTENTION DEFICIT/HYPERACTIVITY DISORDER [ADHD] STUDENT)}

\author{
Mohd Arshad Yahya ${ }^{1}$ and Mohd Firdaus Abdullah* \\ ${ }^{1}$ Sekolah Menengah Kebangsaan Tun Syed Zahiruddin, 77300, Merlimau, Melaka \\ ${ }^{2}$ History Section, School of Humanities, Universiti Sains Malaysia, \\ 11800 Pulau Pinang, Malaysia \\ *Corresponding author: mohdfirdaus_abdullah@usm.my
}

Publication date: 23 December 2020

To cite this article: Mohd Arshad Yahya, \& Mohd Firdaus Abdullah. (2020). Intervensi inklusif sukan terhadap murid gangguan kecelaruan tumpuan dan hiperaktif (ADHD). Asia Pacific Journal of Educators and Education, 35(2), 131-143. https://doi.org/ 10.21315/apjee2020.35.2.8

To link to this article: https://doi.org/10.21315/apjee2020.35.2.8

\begin{abstract}
Attention deficit/hyperactivity disorder (ADHD) is a form of disruption to the brain often experienced by growing children. ADHD children are often labelled as naughty by some. There are several forms of treatment that can be taken against this disorder such as the use of medication. However, the use of medicine will side effect such as loss appetite, disrupting sleep time and anxiety. This study was conducted by observing and recording anecdotes as a means of collecting data. The subject was an ADHD student who had undergone academic inclusiveness and also a special need athlete. The purpose of the study was to explore the effects of sports inclusive intervention on the negative, physical behaviour and social of the student. The findings of the study show that sports inclusion interventions can reduce the negative behaviour of ADHD students and can be an alternative to medication treatment. The effect of this intervention is more harmonious with no side effects and impact for a long time. Sports activities also have goals such as the Individual Teaching Plan concept. In Malaysia, sports intervention is quite new in the Integrated Special Education Program. The impact of this study is expected to open the mind of all parties to make sure that sport activities for special needs students is conducted for the purpose of treatment. The cooperation of all parties including parents is important
\end{abstract}


in this alternative treatment.

Keywords: ADHD, sports inclusive interventions, special education, children, school

\begin{abstract}
Abstrak: Gangguan kecelaruan tumpuan dan hiperaktif (ADHD) merupakan satu bentuk gangguan terhadap otak yang sering dialami oleh kanak-kanak yang sedang membesar. Kanak-kanak ADHD sering dilabelkan sebagai nakal oleh sesetengah orang. Terdapat beberapa bentuk rawatan yang boleh dijalankan terhadap gangguan ini, contohnya penggunaan ubatan. Namun, rawatan dengan menggunakan ubat-ubatan ini memberi kesan seperti rangsangan yang mengurangkan selera makan, mengganggu waktu tidur dan mewujudkan masalah gangguan lain seperti perasaan bimbang secara berlebihan. Kajian ini dilakukan secara kajian kes dengan menjadikan pemerhatian dan catatan anekdot sebagai kaedah pengumpulan data. Peserta kajian merupakan seorang murid ADHD yang pernah menjalani inklusif akademik dan merupakan atlit pelapis bagi acara sukan balapan dan padang pendidikan khas. Tujuan kajian ini ialah meneroka kesan intervensi inklusif sukan terhadap tingkah laku negatif, fizikal dan sosial murid tersebut. Dapatan kajian mendapati intervensi inklusif sukan boleh mengurangkan tingkah laku negatif murid ADHD dan boleh menjadi alternatif kepada rawatan menerusi penggunaan ubatan. Kesan intervensi ini juga lebih harmonis tanpa kesan sampingan dan memberi kesan bagi tempoh masa yang panjang. Aktiviti sukan juga mempunyai matlamat seperti konsep Rancangan Pengajaran Individu (RPI). Di Malaysia, intervensi sukan boleh dikatakan perkara baru dalam Program Pendidikan Khas Integrasi (PPKI). Impak kajian ini diharapkan mampu membuka minda semua pihak agar aktiviti kesukanan yang dijalankan bagi tujuan rawatan memerlukan matlamat serta memperkasakan konsep inklusif sukan untuk semua murid berkeperluan khas. Kerjasama semua pihak termasuk ibu bapa juga penting dalam rawatan alternatif ini.
\end{abstract}

Kata Kunci: ADHD, intervensi inklusif sukan, pendidikan khas, murid, PPKI

\title{
PENDAHULUAN
}

ADHD atau gangguan kecelaruan daya tumpuan dan hiperaktiviti merujuk kepada gejala mental yang serius dialami oleh kanak-kanak khususnya kanakkanak prasekolah. (National Institute of Mental Health, 2016). Setiap manusia mempunyai masalah kurang tumpuan dan aktiviti motor dan impulsif (spontan). Namun bagi individu yang mengalami gangguan ini, tingkah laku mereka lebih teruk, kerap berlaku dan mengganggu atau mengurangkan kualiti aktiviti sosial mereka seperti di tempat kerja atau di sekolah. Menurut The Diagnostic and Statistical Manual of Mental Disorders 4th Edition (DSM-IV) yang dibangunkan oleh American Psychiatric Association mendefinisikan ADHD sebagai satu bentuk gangguan mental kekal berkenaan kecelaruan menumpukan perhatian dan/atau tindakan hiperaktiviti-impulsif yang sering dipaparkan dan lebih teruk daripada apa yang dilihat terhadap individu pada peringkat perkembangan dan hal ini boleh 
diperhatikan (ADHD Institute, 2013). Dengan kata lain, gejala ADHD ini sering melanda murid-murid prasekolah yang sedang melewati tempoh tumbesaran. Kebiasaan umur yang sesuai bagi menilai gejala ADHD ialah pada usia sebelum tujuh tahun kerana pada usia ini kanak-kanak sedang melalui fasa umur sebelum memasuki alam persekolahan.

Dalam pada itu, ramai dalam kalangan guru sering melabelkan murid ADHD untuk aktiviti melibatkan sukan. Sebaliknya kajian membuktikan bahawa murid ADHD tidak mempunyai pencapaian yang baik dalam sukan jika tiada intervensi dijalankan (Altszuler et al., 2017). Hal ini merujuk semula kepada simptom ADHD iaitu tiada daya tumpuan yang tinggi khususnya terhadap rutin-rutin latihan sukan. Pengajaran sukan juga sering disalahertikan sebagai intervensi sukan. Kegagalan melakukan intervensi terhadap murid ADHD juga akan mengakibatkan murid ini mengalami masalah sosial seperti kecenderungan terlibat dengan jenayah salah laku. Dalam kajian ini, seorang murid ADHD telah dipilih untuk mengenal pasti tingkah laku negatif yang dipamerkan semasa menjalani latihan sukan Pendidikan Khas.

Inklusif sukan merupakan suatu kaedah dengan meletakkan murid berkeperluan khas ke dalam sistem pendidikan arus perdana (Winnick \& Loretta, 2017). Hal ini selaras dengan Akta IDEA (Individual with Disabilities Education Act) 1990 yang mencadangkan agar murid berkeperluan khas diletakkan bersama dengan murid tipikal dengan lebih kerap (American Psychological Association [APA], 1990). Dalam hal ini, inklusif turut menekankan kepelbagaian bidang yang luas dan juga dalam pelbagai persekitaran. Keadaan ini membolehkan individu berkeperluan khas menikmati pelbagai permainan dan aktiviti dengan pelbagai cara dan dengan lebih banyak pilihan (Australia Sport Commission [ASC], 2017). Kajian ini menjadikan teori kecerdasan pelbagai oleh Howard Gardner (Gardner, 2010) dan teori sosial kognitif oleh Albert Bandura (Bandura, 1997; 2001) sebagai teras kajian seperti yang ditunjukkan dalam Rajah 1.

Di Malaysia, inklusif lebih menekankan kepada konsep kebolehdidikan (Zalizan, 2009). Dengan kata lain, inklusif di Malaysia lebih menekankan kepada inklusif akademik. Dalam hal ini, inklusif kokurikulum seperti sukan jarang dipraktikkan. Kajian ini menggunakan kerangka konsep seperti yang ditunjukkan dalam Rajah 2. 


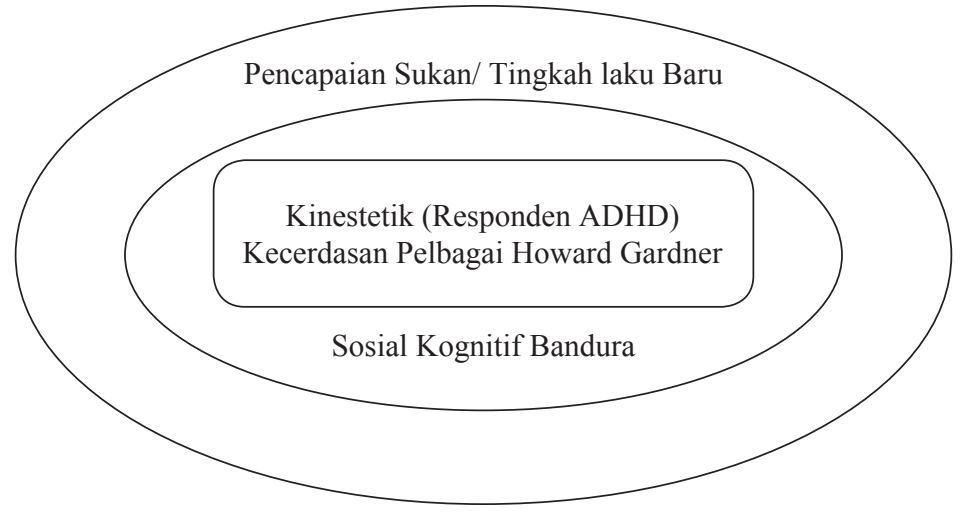

Rajah 1. Kerangka teori intervensi inklusif sukan yang diadaptasi dari Teori Gardner (2010) dan Bandura (1997, 2001)

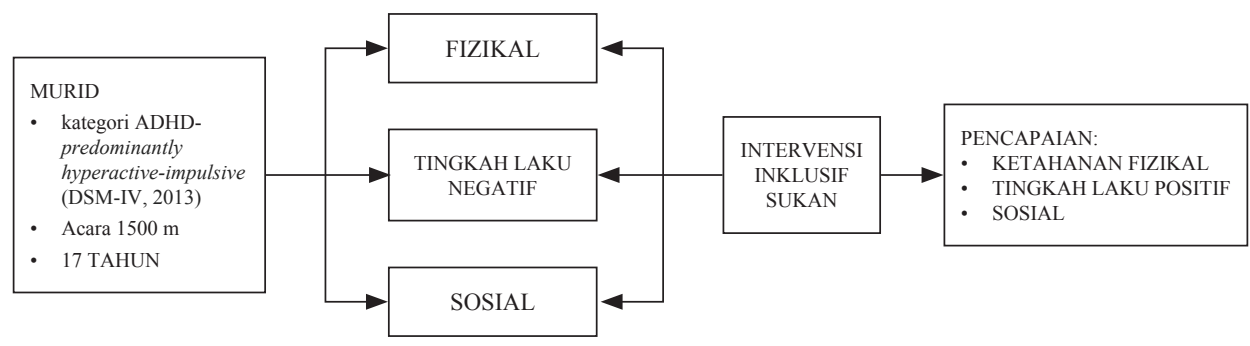

Rajah 2. Kerangka konsep yang diadaptasi dari DSM-IV (ADHD Institute, 2013), Verret, Gardiner dan Beliveau (2010), O’Connor et al. (2014) dan Coelho et al. (2015)

Murid ADHD memerlukan sukan secara berkumpulan bagi mengurangkan gejala tingkah laku negatif mereka. Hal ini selaras dengan kajian oleh O'Connor et al. (2014) berkenaan Program Pemulihan Musim Panas bagi Kanak-kanak ADHD. Terapi sukan bagi murid-murid ADHD memberi perkembangan yang baik berbanding murid-murid ADHD yang tidak diberi program intensif sukan dalam mengubah tingkah laku negatif. Kemajuan yang dimaksudkan merangkumi pengetahuan tentang peraturan sukan, proses penilaian prestasi dan kemahirankemahiran asas dalam sukan. Ibu bapa juga berpendapat bahawa program ini dapat membaiki kemahiran bersukan dan semangat kesukanan anak-anak mereka dalam pergaulan sosial. Kajian ini mencadangkan bahawa latihan intensif boleh meningkatkan kebolehupayaan murid-murid ADHD dalam bersukan. Acara sukan yang dipertandingkan ialah acara balapan $1500 \mathrm{~m}$. 
Proses sosialisasi murid ADHD memainkan peranan penting dalam intervensi sukan. Keadaan ini dapat dilihat menerusi kajian Gaastra, Groen, Tucha dan Tucha (2016) yang mencadangkan intervensi kelas perlu dilakukan terhadap murid-murid ADHD khususnya murid lelaki bagi mengelakkan tingkah laku yang negatif dan perlu diawasi oleh guru. Intervensi sukan perlu dilakukan kerana ia mampu memberi kesan yang positif kepada rakan sekelas serta dapat membantu murid tersebut mencapai prestasi akademik yang lebih baik. Sekiranya murid ADHD diberi intervensi terhadap bidang sukan, murid ini akan memberikan pencapaian sukan yang lebih baik dan juga memberi kesan terhadap proses sosialisasi bersama-sama rakan sepasukan (Williams et al., 2015).

Tingkah laku negatif sememangnya menjadi masalah kepada murid ADHD. Gejala ini secara tidak langsung menjejaskan proses sosialisasi murid tersebut. Antara tingkah laku negatif yang biasa dipamerkan semasa bersukan ialah enggan mendengar arahan, kerap ponteng latihan, tidak berminat dengan rutin latihan dan kadang kala mengeluarkan kata-kata provokasi atau kesat kepada rakan sepasukan atau jurulatih (Perrin \& Jotwani, 2014; Staikova et al., 2013). Biasanya ubatubatan digunakan untuk mengurangkan simptom-simptom seperti ini (Nazeer, Mansour, \& Gross, 2014).

Terdapat beberapa kaedah perubatan yang digunakan bagi mengurangkan simptom atau gejala ADHD ini. Salah satunya adalah penggunaan ubat-ubatan seperti Ritalin, Methylphenidate, Buproprion, Amphetamine dan sebagainya. Walau bagaimanapun, kajian menunjukkan penggunaan ubat-ubatan ini memberi kesan kepada pengambilnya (Kreher, 2012; Perrin \& Jotwani, 2014; Nazeer, Mansour, \& Gross, 2014). Antara gejala yang dialami termasuklah peningkatan kadar degupan jantung, peningkatan tekanan darah, kesukaran untuk tidur, anoreksia, kesakitan pada anggota badan, dan sebagainya. Penggunaan ubat-ubatan ini bukan sahaja melibatkan penggunaan kos yang tinggi, juga boleh menimbulkan gejala lain seperti ketagihan. Ketagihan ini boleh berlaku bukan sahaja kepada murid ADHD bahkan kepada ibu bapa dalam usaha mengurangkan simptom anak mereka. Penggunaan ubat-ubatan ini juga lebih kepada "persepsi" dalam usaha mewujudkan suasana yang lebih baik (Nazeer et al., 2014). Kemuncak kepada penggunaan ubat-ubatan ini jika tidak diselia dengan betul ialah boleh mengakibatkan kematian iaitu dengan peningkatan haba secara mendadak (Kreher, 2012). Penggunaan ubat-ubatan juga boleh dikatakan hanya berkesan dalam jangka masa yang pendek (Roh \& Lee, 2014). 


\section{OBJEKTIF DAN PERSOALAN KAJIAN}

Objektif kajian ini ialah untuk meneroka kesan intervensi inklusif sukan terhadap tingkah laku negatif, fizikal dan sosial murid ADHD. Persoalan kajian dikenal pasti berdasarkan pernyataan masalah iaitu:

1. Adakah intervensi inklusif sukan dapat mengubah tingkah laku negatif dan meningkatkan tumpuan murid ADHD dalam sukan balapan pendidikan khas?

2. Adakah intervensi inklusif sukan dapat meningkatkan pencapaian fizikal dan sosial murid ADHD?

\section{METODOLOGI}

Kajian ini menggunakan pendekatan kualitatif dengan reka bentuk kajian kes. Pengumpulan data adalah melalui kaedah pemerhatian dan analisis dokumen. Pemerhatian dilakukan bagi melihat kekerapan tingkah laku negatif sebelum dan semasa intervensi inklusif sukan dijalankan. Bagi analisis dokumen, catatan anekdot dan laporan Ujian SEGAK (Standard Kecergasan Kebangsaan) turut digunakan sebagai data untuk kajian ini bagi melihat perubahan pada fizikal dan sosial murid tersebut. Kajian kes ini telah dijalankan terhadap seorang murid ADHD yang pernah menjalani inklusif akademik, turut merupakan seorang atlit pelapis bagi acara balapan dan padang pendidikan khas di sebuah sekolah menengah di Melaka. Kajian dijalankan selama empat minggu iaitu latihan intensif sebelum memasuki pertandingan sebenar, dengan satu minggu dijalankan aktiviti baseline dan tiga minggu berikutnya dijalankan intervensi inklusif sukan. Intervensi dijalankan terhadap tingkah laku negatif, ketahanan fizikal dan sosial murid ADHD tersebut. Teori yang digunakan ialah Teori Kecerdasan Pelbagai Howard Gardner (2010) dan Teori Sosial Kognitif Albert Bandura (1997, 2001). Teori ini bersesuaian bagi melihat kecenderungan atlit dan mengubah tingkah laku negatif murid ADHD menerusi kerjasama dan pergaulan sosial.

\section{DAPATAN DAN PERBINCANGAN}

\section{Dapatan Pemerhatian}

Hasil dari pemerhatian dapat dilihat menerusi Rajah 3. Baseline dicatatkan pada minggu pertama iaitu selama lima hari merujuk kepada latihan dalam seminggu. 
Manakala intervensi dijalankan selama tiga minggu iaitu pada minggu kedua, ketiga dan keempat. Antara tingkah laku negatif yang dicatatkan termasuklah kerap ke tandas, mengganggu rakan lain, mengejek dan ingkar arahan jurulatih. Pada satu tahap terdapat juga tingkah laku seperti mengeluarkan kata-kata kesat apabila arahan diberikan oleh jurulatih. Latihan yang dijalankan ialah selama dua jam, lima hari dalam seminggu.

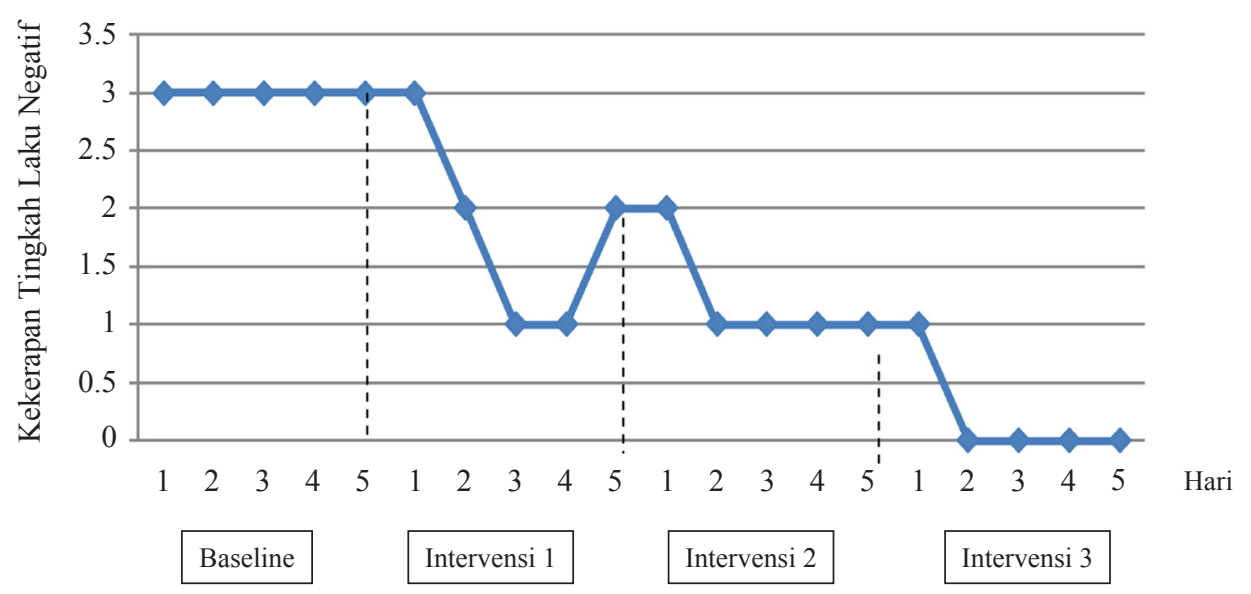

Rajah 3. Graf kekerapan Baseline dan intervensi minggu 1, 2 dan 3.

Baseline mencatatkan sebanyak tiga kali kekerapan tingkah laku negatif yang dipamerkan sepanjang minggu pertama latihan. Intervensi yang dijalankan pada minggu kedua latihan mencatatkan turun naik kekerapan sama. Namun pada minggu kedua intervensi, kekerapan menurun kepada sekali kekerapan tingkah laku negatif. Akhirnya pada minggu ketiga intervensi, kekerapan tingkah laku mencatatkan sekali kekerapan pada hari pertama dan terus terhapus pada harihari berikutnya. Pada tahap ini, murid telah berjaya menghapuskan tingkah laku negatif menerusi intervensi inklusif sukan yang dijalankan.

\section{Analisis Dokumen}

Berdasarkan pemerhatian yang dilakukan, kejayaan intervensi ini turut disokong menerusi dokumen Ujian SEGAK (Kementerian Pelajaran Malaysia, 2013a; 2013b) yang dijalankan sebanyak dua penggal. Ujian ini bertujuan untuk melihat perubahan fizikal murid ADHD tersebut. Ujian SEGAK ini terbahagi kepada lima ujian kecil iaitu Indeks Jisim Badan, Ujian Naik Turun Bangku, Ujian Tekan Tubi, Ujian Ringkuk Tubi Separa dan Ujian Jangkauan Melunjur. Skor peserta ini pada penggal pertama ialah $\mathrm{E}$ iaitu satu bintang yang membawa maksud Tidak Cergas. Sejurus intervensi inklusif sukan dijalankan, skor peserta kajian 
mencatatkan $\mathrm{C}$ iaitu Cergas yang membawa kepada penarafan tiga bintang. Antara ujian kecil SEGAK yang mencatatkan perubahan ialah pada Ujian Ringkuk Tubi Separa dan Ujian Jangkauan Melunjur. Skor pada Penggal Pertama bagi Ujian Ringkuk Tubi ialah pada skor 5 manakala pada Penggal Kedua mencatatkan skor 16. Ujian ini bertujuan mengukur daya tahan dan kekuatan otot abdomen. Ujian Jangkauan Melunjur pula ialah bagi mengukur fleksibiliti bahagian bawah belakang badan dan otot hamstring. Ujian ini penting bagi atlit sukan larian. Penggal Pertama mencatatkan catatan $19 \mathrm{~cm}$ manakala Penggal Kedua meningkat menjadi $26 \mathrm{~cm}$. Fizikal peserta berlaku perubahan pada aspek daya tahan dan kekuatan otot abdomen dan fleksibiliti tubuh badan.

Bagi aspek sosial pula, hasil daripada perbandingan catatan anekdot tingkah laku dapat dilihat menerusi Jadual 1. Catatan dilakukan pada waktu tingkah laku negatif biasanya bermula. Antara tingkah laku tersebut ialah kekerapan ke tandas, ingkar arahan jurulatih, mengeluarkan kata-kata kesat dan menipu dalam kiraan semasa acara pemanasan badan. Catatan ini dilakukan sebelum dan semasa intervensi dijalankan.

Jadual 1. Perbandingan catatan anekdot tingkah laku

\begin{tabular}{cc}
\hline Jam & Kekerapan \\
\hline 5.00 & 21 \\
5.30 & 5 \\
6.00 & - \\
6.30 & 5 \\
\hline Jumlah & 31 \\
\hline
\end{tabular}

Berdasarkan Jadual 1, pemerhatian bagi tujuan catatan dipecahkan kepada empat waktu iaitu jam 5.00, 5.30, 6.00 dan 6.30 petang. Berdasarkan catatan, didapati murid ADHD mula menunjukkan tingkah laku negatif di antara jam 5.00 hingga 5.30 petang, iaitu semasa latihan pemanasan badan dan taklimat awal oleh jurulatih. Waktu ini mencatatkan kekerapan paling banyak iaitu sebanyak 21 kekerapan. Selain itu, pada jam 5.30 petang, kekerapan dicatatkan sebanyak lima kekerapan. Pada waktu ini, rejim latihan berat kadangkala dilakukan. Hal ini menyebabkan peserta kajian menunjukkan tingkah laku bosan dan sering letih. Pada jam 6.30 pula, sebanyak lima kekerapan dicatatkan. Pada waktu ini, murid ADHD menunjukkan ciri-ciri untuk ponteng aktiviti cool down dan kerap ke tandas. Oleh itu, intervensi inklusif sukan yang dijalankan amat bersesuaian bagi meningkatkan daya tumpuan dan fokus murid ini untuk menjalani latihan persediaan sebelum acara sukan bermula. Pada masa yang sama, intervensi ini 
juga dapat mengurangkan simptom-simptom ADHD dan menggalakkan hubungan sosial yang lebih baik bagi murid tersebut.

Semasa aktiviti intervensi dijalankan, ketika murid ADHD tersebut melakukan tingkah laku negatif, rakan-rakan aliran perdana yang turut menjalani latihan yang sama akan menegur tingkah laku negatif murid tersebut serta-merta agar lebih berkelakuan sopan. Sekiranya hendak ke tandas pula, ada rakan lain yang akan turut serta menemani bagi memastikan murid ADHD tersebut benar-benar ke tandas dan membuang air. Seperkara yang menarik perhatian pengkaji ialah sekiranya murid ADHD tersebut tidak mampu membuat rejim latihan atau aktiviti regangan yang susah, murid aliran perdana akan memberi bantuan kepada murid ADHD tersebut. Tingkah laku kesukarelaan dan memberi dorongan ini secara tidak langsung membentuk tingkah laku positif murid ADHD tersebut. Hal ini sama seperti yang dinyatakan oleh Kamp, Sperlich dan Holmberg (2014) dan Golubovic, Milutinovic dan Golubovic (2014) bahawa aktiviti kesukanan mampu mengurangkan simptom ADHD, meningkatkan hubungan sosial murid dengan lebih baik dan darjah kecergasan yang lebih baik.

Secara umumnya, hasil kajian mendapati, bagi mengurangkan simptom ADHD seperti tingkah laku negatif, rawatan alternatif yang boleh dicadangkan ialah menerusi sukan berpasukan seperti bola sepak, bola keranjang, hoki dan sebagainya. Manakala sukan yang tidak melibatkan pasukan seperti acara larian dan padang, latihan boleh dijalankan secara berkumpulan. Pada masa yang sama, intervensi inklusif sukan juga perlu diletakkan matlamat tertentu seperti penghapusan tingkah laku negatif. Di sini dapat dilihat perbezaan di antara sukan yang sememangnya fokus untuk penjagaan kesihatan diri tetapi intervensi sukan ialah salah satu kaedah rawatan bagi murid ADHD dan pada masa yang sama penjagaan kesihatan diri turut terlibat sama. Proses sosialisasi murid ini adalah penting kerana sekiranya intervensi dijalankan dengan betul, murid yang bermasalah tingkah laku akan bertindak atau bertingkah laku menurut persekitaran sosialnya. Dalam hal ini, inklusif sukan berperanan untuk membentuk tingkah laku positif murid tersebut agar mudah diterima dalam sosial masyarakat di sekitarnya.

\section{KESIMPULAN}

Sebagai kesimpulan, ternyata intervensi inklusif sukan dapat mengubah tingkah laku murid ADHD tanpa menggunakan rawatan ubat-ubatan. Pada masa yang sama, intervensi inklusif sukan juga memberi perubahan positif terhadap fizikal dan sosial murid ADHD. Dalam pada itu, intervensi inklusif sukan dan Pendidikan Jasmani dan Kesihatan memerlukan satu bentuk garis panduan dari pihak yang 
bertanggungjawab. Aktiviti bersukan untuk murid ADHD sering dianggap sebagai intervensi sukan bagi mengurangkan gejala tingkah laku yang tidak diingini. Persoalan yang sering timbul ialah, adakah pengajaran Pendidikan Jasmani dan Kesihatan yang dilakukan selama ini berlaku proses pengubahsuaian seperti yang dicadangkan oleh Persekutuan Sukan Pendidikan Khas Antarabangsa? Umum mengetahui kebanyakan murid ADHD tidak gemar kepada aktiviti rutin sukan. Masalah lain yang timbul ialah koordinasi motor dan tingkah laku fungsi eksekutif (EF) mereka gagal berfungsi dengan baik. Kegagalan berbuat demikian menyebabkan isu lain timbul seperti masalah dalam pelajaran, tekanan dan kebimbangan. Perlu diambil tahu bahawa tidak semua murid ADHD kompeten dalam aktiviti kesukanan. Justeru, kerjasama ibu bapa memainkan peranan penting dalam menjayakan aktiviti bersukan murid ADHD ini. Komunikasi ibu bapa dan guru sangat penting untuk mengawal tingkah laku murid-murid ADHD yang terlibat dengan sukan.

Berdasarkan dapatan kajian, beberapa penambahbaikan dapat dicadangkan. Pertama, kerajaan menerusi Bahagian Pendidikan Khas, Kementerian Pendidikan Malaysia boleh memperkasakan program Pendidikan Jasmani Suaian untuk Program Pendidikan Khas Integrasi (PPKI) tidak mengira kategori di seluruh negara. Hal ini selain dapat mengelakkan kekeliruan aspek Pendidikan Jasmani dan Kesihatan untuk aliran perdana dan murid berkeperluan khas, pengajaran Pendidikan Jasmani Suaian ini tidak menafikan hak murid berkeperluan khas untuk mendapat pendidikan sama seperti orang lain. Selain itu, pendidikan ini juga dapat mencungkil bakat-bakat baru dalam bidang kesukanan selaras dengan hasrat kerajaan bagi melahirkan atlit paralimpik bertaraf dunia.

Cadangan kedua ialah Pendidikan Jasmani dan Kesihatan perlu dibezakan dengan intervensi sukan. Intervensi sukan lebih berfokus kepada rawatan tingkah laku seseorang manakala Pendidikan Jasmani dan Kesihatan adalah bersifat umum. Intervensi juga lebih kepada kaedah merawat berbanding Pendidikan Jasmani dan Kesihatan lebih kepada penjagaan atau pengekalan kesihatan. Hal ini menunjukkan perbezaan konteks tujuan Pendidikan Jasmani itu sendiri berbanding intervensi sukan yang sememangnya lebih merujuk kepada rawatan secara semulajadi.

Cadangan ketiga ialah masa untuk Pendidikan Jasmani dan Kesihatan dengan Pendidikan Jasmani Suaian atau intervensi perlu dibezakan. Intervensi sukan mempunyai matlamat dan objektif yang perlu dicapai dalam masa-masa tertentu manakala Pendidikan Jasmani dan Kesihatan tiada tempoh masa tertentu. Maka, di sini dapat dilihat penekanan intervensi sukan yang lebih bersifat rawatan. Perkembangan dan perubahan dalam intervensi perlu dilihat dari semasa ke semasa. 
Cadangan keempat ialah jenis sukan yang terlibat. Tidak semua sukan sesuai dengan intervensi sebaliknya semua sukan adalah sesuai menurut Pendidikan Jasmani dan Kesihatan tidak kira untuk murid aliran perdana atau murid bekeperluan khas. Sebagai contoh, bagi tujuan intervensi sukan untuk murid ADHD ialah sukan secara berpasukan seperti bola sepak, bola keranjang, bola jaring dan sebagainya. Murid ADHD tidak boleh terlibat dengan latihan atau sukan secara perseorangan seperti tenis, acara balapan, renang, skuasy dan sebagainya. Murid ADHD secara asasnya tidak mempunyai fokus, makanya rejim latihan secara rutin merupakan masalah terbesar bagi mereka. Selain menggalakkan perubahan tingkah laku ke arah yang lebih positif, intervensi sukan juga menggalakkan proses sosialisasi di kalangan murid ADHD. Dengan kata lain, rakan sepasukan turut membantu mengurangkan gejala tingkah laku negatif menerusi pergaulan (Capodieci, Rivetti, \& Cornoldi, 2016).

Cadangan seterusnya ialah intervensi sukan hendaklah dijalankan secara koperatif. Hal ini seperti yang dinyatakan oleh Capodieci et al. (2016) yang menyatakan gejala tingkah laku negatif murid ADHD di dalam kelas menjadi semakin berkurangan melalui pembelajaran secara koperatif. Pembelajaran koperatif mencadangkan bahawa setiap murid yang digabungjalinkan dalam proses pembelajaran dan pemudahcaraan (pdpc) terdiri daripada individu yang heterogen. Asasnya ialah kepelbagaian yang ada akan membentuk suatu tingkah laku yang baru dan tingkah laku baru tersebut akan dipelajari. Dengan kata lain, tingkah laku yang tidak memenuhi standard dalam kumpulan yang diwujudkan akan terhapus dengan sendirinya.

Berikutnya ialah dengan memperkasakan konsep inklusif. Di Malaysia, konsep inklusif masih memegang kepada konsep kebolehdidikan (Zalizan, 2009). Hal ini mengakibatkan pengasingan antara murid yang boleh "belajar" dengan murid yang tidak boleh belajar mengakibatkan wujudnya jurang yang semakin melebar. Seharusnya pendidikan khas di negara ini menekankan ke arah kekuatan dan bukan fokus kepadakelemahan murid tersebut. Konsep ini juga menyebabkan pelanggaran hak asasi manusia untuk mendapatkan pendidikan seperti yang termaktub dalam Kenyataan Salamanca, Rangka Tindakan Kerja Biwako dan Konvensyen Hak Kanak-Kanak. Sebagai contoh, murid ADHD yang mempunyai masalah tingkah laku dan tidak boleh dididik, penyisihan berlaku dan murid tersebut dihantar ke pusat yang terpisah dari sistem sekolah aliran perdana seperti Pemulihan Dalam Komuniti (PDK). Kesannya, wujud istilah sekolah gagal mendidik dan dari aspek murid itu pula, timbul masalah lain seperti anti sosial bagi jangka masa panjang. Hasilnya, murid berpotensi untuk terlibat dengan jenayah adalah tinggi (Lindsay, Carson, Holland, Taylor, O’Brien, \& Wheeler, 2013). 


\section{RUJUKAN}

ADHD Institute. (2013). The diagnostic and statistical manual of mental disorders (5th edition) (DSM-5TM). Retrieved 15 February 2017 from http://www.adhd -institute.com/assessment-diagnosis/diagnosis/dsm-5tm/

Altszuler, A. R., Marrow, A. S., Merrill, B. M., Bressler, S., Macphee, F. L., \& Gnagy, E. M. (2017). The effect of stimulant medication and training on sports competence among children with ADHD. Journal of Clinical \& Adolescent Psychology, 48(Supp. 1), S155-S167. https://doi.org/10.1080/15374416.2016.1270829

American Psychological Association. (1990). Individual with Disabilities Education Act (IDEA). Retrieved 4 June 2017 from http://www.apa.org/about/gr/issues/ disability/idea.aspx

National Institute of Mental Health. (2016). Attention Deficit/Hyperactivity Disorder. Retrieved 16 February 2017 from https://www.nimh.nih.gov/health/topics/ attention-deficit-hyperactivity-disorder-adhd/index.shtml\#part_145444

Australia Sport Commission. (2017). Retrieved 5 June 2017 from http://www.ausport.gov. au/participating/resources/disability/factsheets/inclusion_in_sport

Bandura, A. (2001). Social cognitive theory of mass communication. Mediapsychology, 3, 265-299. https://doi.org/10.1207/S1532785XMEP0303_03

Bandura, A. (1997). Self-efficacy: Toward a unifying theory of behavioral change. Psychological Review, 34(2), 191-215. https://doi.org/10.1037/0033-295X.84.2 .191

Capodieci, A., Rivetti, T., \& Cornoldi, C. (2016). A cooperative learning classroom intervension for increasing peer's acceptance of children with ADHD. Journal of Attention Disorders, 23(3), 282-292. https://doi.org/10.1177/ 1087054716666952

Coelho, F. L., Barbosa, D. F., Rizzutti, S., Muszkat, M., Bueno, O. F. A., \& Miranda, M. C. (2015). Use of cognitive behavioral therapy and token economy to alleviate dysfunctional behavior in children with attention-deficit hyperactivity. Frontiers in Psychiatry, 6, 167. https://doi.org/10.3389/fpsyt.2015.00167

Gaastra, F. G., Groen, Y., Tucha, L., \& Tucha, O. (2016). The effects of classroom interventions on off-task and disruptive classroom behavior in children with symptoms of attention deficit/hyperactivity disorder: A meta-analytic review. PLOS 11(2), 1-19. https://doi.org/10.1371/journal.pone.0148841

Gardner, H. (2010). Frames of mind: The theory of multiple intelligences (10th ed.). New York: Basic Books.

Golubovic, S., Milutinovic, D., \& Golubovic, B. (2014). Benefits of physical exercises in developing certain fitness levels in children with hyperactivity. Journal of Psychiatric and Mental Health Nursing, 21, 594-600. https://doi.org/10.1111/ jpm.12091

Kamp, C. F., Sperlich, B., \& Holmberg, H. C. (2014). Exercise reduces the symptoms of attenton-deficit/hyperactivity disorder and improves social behaviour, motor skills, strength and neuropsychological parameters. Acta Paediatrica Nurturing the Child, 103, 709-714. https://doi.org/10.1111/apa.12628 
Kementerian Pelajaran Malaysia. (2013a). Kurikulum standard sekolah rendah pendidikan khas (masalah pembelajaran) pendidikan jasmani dan kesihatan tahun empat. Putrajaya: Bahagian Pembangunan Kurikulum.

Kementerian Pelajaran Malaysia. (2013b). Buku panduan pelaksanaan dasar satu murid satu sukan (1M 1S). Putrajaya: Bahagian Sukan, Kementerian Pelajaran Malaysia.

Kreher, J. B. (2012). Attention Deficit/Hyperactivity Disorder (ADHD) in athletes. International Journal of Athletic Therapy and Training, 3, 15-19. https://doi. org/10.1123/ijatt.17.3.15

Lee, H., Dunn, J. C., \& Holt, N. L. (2014). Youth sport experiences of individuals with attention deficit/hyperactivity disorder. Adapted Physical Activity Quarterly, 31, 343-361. https://doi.org/10.1123/apaq.2014-0142

Lindsay, W. R., Carson, D., Holland, A. J., Taylor, J. L., O’Brien, G., \& Wheeler, J. R. (2013). The impact of known criminogenic factors in offenders with inttelectual disability: Previous findings and new results on ADHD. Journal of Applied Research in Intellectual Disabilities, 26, 71-80. https://doi.org/10.1111/jar.12011

Nazeer, A., Mansour, M., \& Gross, K. A. (2014). ADHD and adolescent atheletes. Frontier in Public Health, 2(46), 1-7. https://doi.org/10.3389/fpubh.2014.00046

O’Connor, B. C., Fabiano, G. A., Waschbusch, D. A, Belin, P. J., Gnagy, E. M., Pelham, W. E., Greiner, A. R., \& Roemmich, J. N. (2014). Effects of a summer treatment program on functional sports outcome in young children with ADHD. Journal of Abnormal Child Psychology, 42, 1005-1017. https://doi.org/10.1007/ s10802-013-9830-0

Perrin, A. E., \& Jotwani, V. M. (2014). Adressing the unique issues of student athletes with ADHD. The Journal of Family Practice, 63(5), 1-9.

Roh, C. H., \& Lee. W. B. (2014). A study of the attention measurement variables of a serious game as a treatment for ADHD. Wireless Personal Communications 79, 2485-2498. https://doi.org/10.1007/s11277-014-1744-9

Staikova, E., Gomes, H., Tartter, V., McCabe, A., \& Halperin, J. M. (2013). Pragmatic deficits and social impairment in children with ADHD. Journal of Child Psychology and Psychiatry, 54(12), 1275-1283. https://doi.org/10.1111/jcpp.12082

Verret, C., Gardiner, P., \& Beliveau, L. (2010). Fitness level and gross motor performance of children with attention deficit hyperactivity disorder. Adapted Physical Activity Quarterly, 27, 337-351. https://doi.org/10.1123/apaq.27.4.337

Williams, A. L., Chacko, A., Wymbs, B. T., Fabiano, G. A., Seymour, K. E., Gnagy, E. M., Chronis, A. M., Maclean, L. B., Pelham, W. E., \& Morris, T., L. (2015). Athletic performance and social behavior as predictors of peer acceptance in children diagnosed with Attention-Deficit/Hyperactivity disorder. Journal of Emotional and Behavioral Disorders, 12(3), 173-180.

Winnick, J. P., \& Loretta, D. L. (2017). Adapted physical education and sport. United States: Human Kinetics.

Zalizan Mohd Jelas. (2009). Pendidikan kanak-kanak berkeperluan khas: Konsep dan amalan. Bangi: Penerbit Universiti Kebangsaan Malaysia. 